\title{
HR-MAS NMR for Rapid Identification of Illicit Substances in Tablets and Blotter Papers Seized by Police Department
}

\author{
Luciano F. Souza, ${ }^{a, b}$ Tarcísio S. Vieira, ${ }^{a, c}$ Glaucia B. Alcantara ${ }^{d}$ and Luciano M. Lião $^{*, a}$ \\ ${ }^{a}$ Instituto de Química, Universidade Federal de Goiás, Av. Esperança, s/n, Campus Samambaia, \\ 74690-900 Goiânia-GO, Brazil \\ ${ }^{b}$ Instituto de Criminalística Leonardo Rodrigues, Superintendência da Polícia Técnico-Científica do \\ Estado de Goiás, 74425-030 Goiânia-GO, Brazil \\ 'Instituto Federal do Tocantins, Campus Araguatins, Povoado Santa Teresa, km 05, \\ Zona Rural, 75950-000 Araguatins-TO, Brazil \\ 'Instituto de Química, Universidade Federal de Mato Grosso do Sul, CP 549, \\ 79070-900 Campo Grande-MS, Brazil
}

\begin{abstract}
Illicit substances found in blotter papers and tablets seized by police are traditionally identified and characterized from extracts of these materials. However, the procedures involved in extraction stages can result in artifacts and even contamination of the samples to be analyzed. On the other hand, high-resolution magic angle spinning nuclear magnetic resonance (HR-MAS NMR) is a technique that requires no pretreatment steps, enabling direct analysis of the material, including the analysis of new illegal synthetic psychoactive substances. This study presents and discusses applications of the HR-MAS NMR in the analysis of tablets and blotter papers seized. Additional analysis in solution of the extracts of these materials was performed to compare the obtained spectral resolution signals. The results demonstrated that the HR-MAS NMR allowed the rapid identification of 3,4-methylenedioxy- $N$-methylcathinone (methylone), 4-methylmethcathinone (mephedrone), 2,5-dimethoxy-4-bromoamphetamine (DOB) and 2-(4-bromo-2,5-dimethoxyphenyl)- $\mathrm{N}$-[(2methoxyphenyl)methyl]ethanamine (25B-NBOMe) in samples of tablets and blotter papers seized in Goiás State, Brazil.
\end{abstract}

Keywords: designer drugs, psychoactive substances, ${ }^{1} \mathrm{H}$ HR-MAS NMR, fast identification

\section{Introduction}

The term "designer drugs" has been used to describe modifications in the chemical structure of illicit psychoactive substances to create new substances with similar psychoactive effects, but which have not yet been added in controlled substances list, specific for each country. In this context, these compounds are considered "legal drugs" in some countries. ${ }^{1,2}$ Since 2005, the European Union (EU) has reported more than 450 new psychoactive substances through the Early Warning System, while Joint Reports have been drafted for twelve substances, including 4-methylmethcathinone (mephedrone, 1) and 2-(4-iodo2,5-dimethoxyphenyl)- $N$-[(2-methoxyphenyl)methyl] ethanamine (25I-NBOMe), an analogue of 2-(4-bromo-

*e-mail: lucianoliao@ufg.br 2,5-dimethoxyphenyl)- $N$-[(2-methoxyphenyl)methyl]ethanamine (25B-NBOMe, 2) ${ }^{3,4}$

Among the substances added to the list of proscribed drugs of the Brazilian Health Surveillance Agency (Agência Nacional de Vigilância Sanitária (ANVISA)), ordinance 344 (May 12, 1998), we can highlight: mephedrone, ${ }^{5,6}$ updated by Collegiate Board Resolution (RDC) 36 (August 3, 2011); 3,4-methylenedioxymethcathinone (methylone, 3), ${ }^{7}$ updated by RDC 6 (February 18, 2014); 25B-NBOMe,${ }^{8,9}$ updated by RDC 6; and 2,5-dimethoxy4-bromoamphetamine (DOB, 4) (Figure 1). ${ }^{10}$ These substances have been seized by Goiás police department as blotter paper and tablets with different trademarks (Figure 2).

The increasing proliferation of the designer drugs has hindered their identification based only on the traditional comparison of results obtained from the analysis with 
<smiles>CNC(C)C(=O)c1ccc(C)cc1</smiles>

Mephedrone (1)

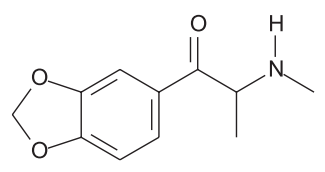

Methylone (3)

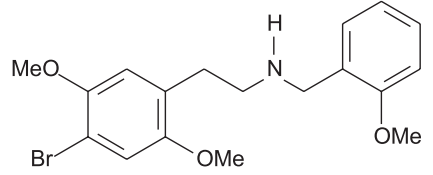

25B-NBOMe (2)

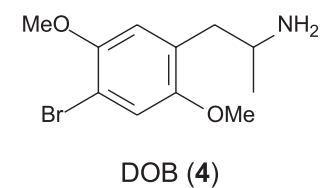

Figure 1. Chemical structures of some psychoactive substances. (a)

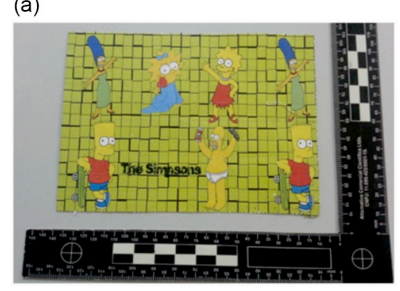

(b)

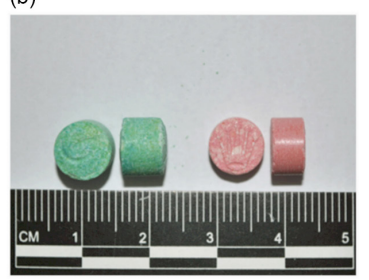

Figure 2. Samples of (a) blotter paper and (b) tablets seized, containing proscribed drugs.

available spectral libraries. ${ }^{11}$ Added to this, the difficulties associated with the unequivocal assignment of the substitution pattern in the aromatic rings present in new amphetamine derivatives and other molecules with similar chemical structure, absent in equipment databases, makes detection techniques traditionally used in forensic science fairly limited. ${ }^{12,13}$

In this context, nuclear magnetic resonance (NMR) spectroscopy, one of the most used tools for identification and structural characterization of organic compounds, demonstrates great potential to solve problems in forensic chemistry, especially in identification of new compounds without analytical standards. This technique also belongs to the list of analytical techniques recommended by the Scientific Working Group for the Analysis of Seized Drugs (SWGDRUG) aiming at the elaboration of expert reports of a definitive character. ${ }^{14}$

Among NMR techniques, high-resolution (HR) NMR for liquid and in solution samples is the most frequently used. Its main disadvantage is the need for sample extraction, which leads to loss of information about the natural state of the sample. Another drawback is the amount of sample required to obtain a good signal/noise ratio without increased cost and analysis time. On the other hand, the investigation of samples without any pretreatment and with high-resolution can be carried out by high-resolution magic angle spinning (HR-MAS) NMR spectroscopy. This technique allows, in a rapid single experiment, information regarding the wide variety of compounds in a heterogeneous solid matrix, also avoiding the occurrence of decomposition and/or undesirable chemical changes that may arise in the chemical extraction process..$^{15-17}$

In this regard, the present study describes the use of ${ }^{1}$ H HR-MAS NMR analyses for unprocessed heterogeneous materials (without any preliminary treatment), aiming to identify illicit substances in samples of blotter papers and tablets seized by police department in Goiás State, Brazil. In order to compare spectral resolutions, in solution NMR analyses for extracted compounds were also evaluated.

\section{Experimental}

Solvents

$\mathrm{MeOH}$, high-performance liquid chromatography (HPLC) grade, purity $\geq 99.9 \%$, was obtained from JTBaker (Darmstadt, Germany). $\mathrm{CD}_{3} \mathrm{OD}$ of $99.8 \%$ isotopic purity, containing $0.05 \%$ tetramethylsilane (TMS) was obtained from CIL (Cambridge Isotope Laboratories Inc., Andover, MA, USA).

\section{Sample preparation}

\section{Heterogeneous samples}

Samples of blotter paper of approximately $0.8 \mathrm{~cm}^{2}$ were fragmented into pieces. Four pieces were inserted into a zirconium rotor with internal volume of $50 \mu \mathrm{L}$ (Figure 3). The samples of tablets were powdered and $15 \mathrm{mg}$ were transferred to an identical rotor. In both experiments $40 \mu \mathrm{L}$ of $\mathrm{CD}_{3} \mathrm{OD}$ were added to the rotors.

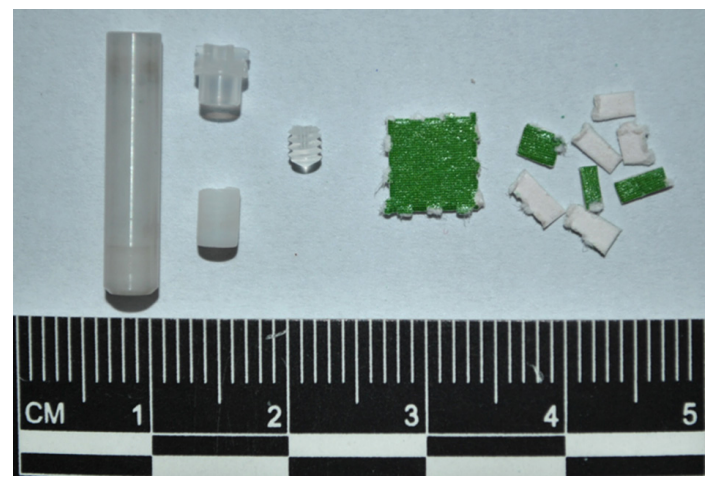

Figure 3. Zirconium rotor $(50 \mu \mathrm{L})$ and accessories, along with the sample of intact and fragmented blotter paper.

In solution samples

Samples of the blotter papers were extracted with $510 \mu \mathrm{L}$ of $\mathrm{CD}_{3} \mathrm{OD}$ during $1 \mathrm{~h}$. The solution was transferred to a $5 \mathrm{~mm}$ diameter NMR tube. Samples of tablets were powdered, $10 \mathrm{mg}$ transferred to an Eppendorf flask, $1 \mathrm{~mL}$ of 
$\mathrm{MeOH}$ was added, and the mixture was stirred in vortex for $15 \mathrm{~s}$. After centrifugation for $30 \mathrm{~s}$, the solution, in another flask, was evaporated using nitrogen gas. A volume of $500 \mu \mathrm{L}$ of $\mathrm{CD}_{3} \mathrm{OD}$ were transferred to a $5 \mathrm{~mm}$ NMR tube.

\section{NMR conditions}

All NMR data were acquired at $25^{\circ} \mathrm{C}$ using a Bruker Avance III 500 NMR spectrometer (Karlsruhe, Germany) operated at $11.75 \mathrm{~T}\left({ }^{1} \mathrm{H}\right.$ resonance frequency $\left.500.13 \mathrm{MHz}\right)$, equipped with a $5 \mathrm{~mm}$ triple resonance broad band (TBI) probe (in solution analyses) and a 4 mm HR-MAS probe spinning at $7 \mathrm{kHz}$ (unprocessed samples). The spectra were recorded using a composite pulses presaturation (CPPR) sequence for water signal suppression. Sixty four (64) free induction decays (FIDs) were collected into $122 \mathrm{k}$ data points using a $12.4 \mu$ s pulse width (90 pulse angle), spectral width of $12500 \mathrm{~Hz}$, relaxation delay of $1.0 \mathrm{~s}$ and an acquisition time of $4.99 \mathrm{~s}$. An exponential weighing factor corresponding to line broadening of $0.3 \mathrm{~Hz}$ was applied to the FIDs. The following abbreviations are used to designate NMR absorption patterns: s (singlet), brd (broad doublet), brt (broad triplet), d (doublet), dt (double triplet), $\mathrm{t}$ (triplet), q (quartet), dd (double doublet), ddd (double double doublet) and $\mathrm{m}$ (multiplet).

\section{Results and Discussion}

The NMR spectra obtained for blotter papers using unprocessed or extracted samples are very similar, presenting the same signal patterns and chemical shifts (Figure 4). The multiplicities, coupling constants $(J)$ and chemical shifts $(\delta)$ are attributed to one 1,2,4,5-tetrasubstituted aromatic ring containing two methoxy and one isopropylamine attached groups. These informations, coupled with previous data coming from mass spectrometry (MS) (Figure S1), allowed the characterization of DOB. The full hydrogen signals assignment are presented in Table 1 .

Similarly to DOB, the NMR spectra obtained for another blotter paper using unprocessed or extracted samples are very similar, presenting the same signal patterns and chemical shifts (Figure 5). The multiplicities, coupling

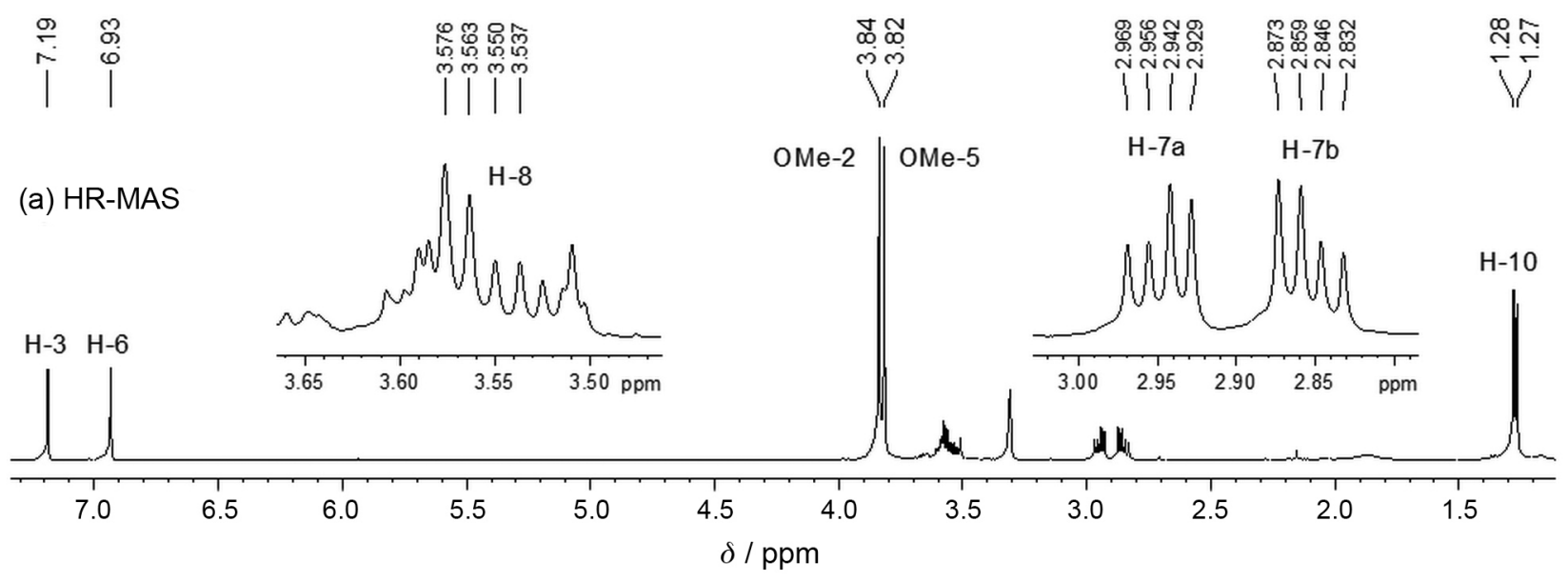

(b) TBI
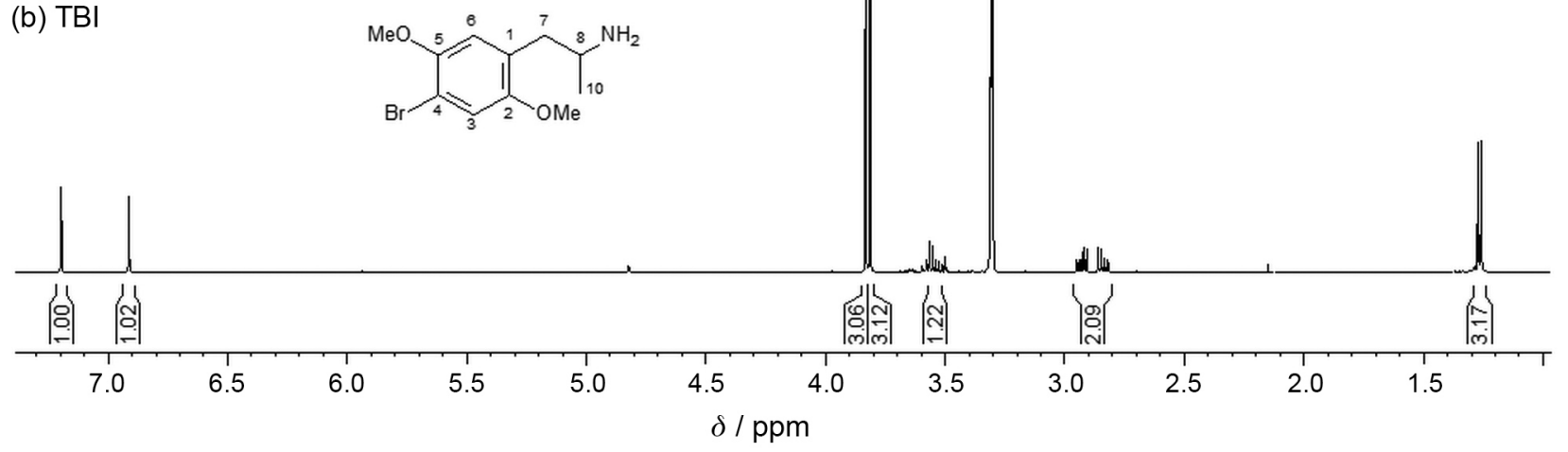

Figure 4. ${ }^{1} \mathrm{H}$ NMR spectra of blotter paper using (a) HR-MAS and (b) TBI probes showing the presence of DOB. The signal multiplicities are highlighted. 
Table 1. ${ }^{1} \mathrm{H}$ NMR spectral data for DOB $\left(500 \mathrm{MHz}, \mathrm{CD}_{3} \mathrm{OD}\right)$

\begin{tabular}{|c|c|c|c|}
\hline \multirow{2}{*}{ Position } & DOB (4) & $\mathrm{DOB}^{\mathrm{a}}$ & \\
\hline & \multicolumn{2}{|c|}{$\delta^{1} \mathrm{H}$ (multiplicity, $\left.J / \mathrm{Hz}\right)$} & \\
\hline 3 & $7.19(\mathrm{~s})$ & $7.41(\mathrm{~s})$ & \\
\hline 6 & $6.93(\mathrm{~s})$ & $7.09(\mathrm{~s})$ & $\mathrm{MeO}$ \\
\hline $7 \mathrm{a}$ & $2.95(\mathrm{dd}, 13.5,6.8)$ & $3.01(\mathrm{~s})$ & \\
\hline $7 \mathrm{~b}$ & $2.86(\mathrm{dd}, 13.5,7.3)$ & $2.99(\mathrm{~s})$ & 10 \\
\hline 8 & $3.57(\mathrm{ddq}, 7.3,6.8,6.5)$ & $3.74(\mathrm{q}, 6.6)$ & $\mathrm{Br}^{-}$ \\
\hline 10 & $1.27(\mathrm{~d}, 6.5)$ & $1.37(\mathrm{~d}, 6.6)$ & \\
\hline $\mathrm{OCH}_{3}-2$ & $3.84(\mathrm{~s})$ & $3.95(\mathrm{~s})$ & \\
\hline $\mathrm{OCH}_{3}-5$ & $3.82(\mathrm{~s})$ & $3.90(\mathrm{~s})$ & \\
\hline
\end{tabular}

${ }^{\mathrm{a} 1} \mathrm{H}$ NMR spectral data for 2,5-dimethoxy-4-bromoamphetamine (DOB) $\left(400 \mathrm{MHz}, \mathrm{D}_{2} \mathrm{O}\right) .{ }^{10} \delta$ : chemical shift; $J$ : coupling constant.

constants $(J)$ and chemical shifts are attributed to one 1,2,4,5-tetrasubstituted and one 1,2-disubstituted aromatic rings containing three methoxy and one ethylmethylamine attached groups. Bromine was also observed in MS spectra (Figure S2). This compound was characterized as 25B-NBOMe. The full hydrogen signals assignment are presented on Table 2.
Since the experiments with the HR-MAS probe were promising to identify illicit substances in blotter papers, without any extraction procedures, it was also used for identifying substances in tablets seized by police department, which have very distinct characteristics from blotter papers previously analyzed. For this, $15 \mathrm{mg}$ of powdered tablet were analyzed, and mephedrone, the

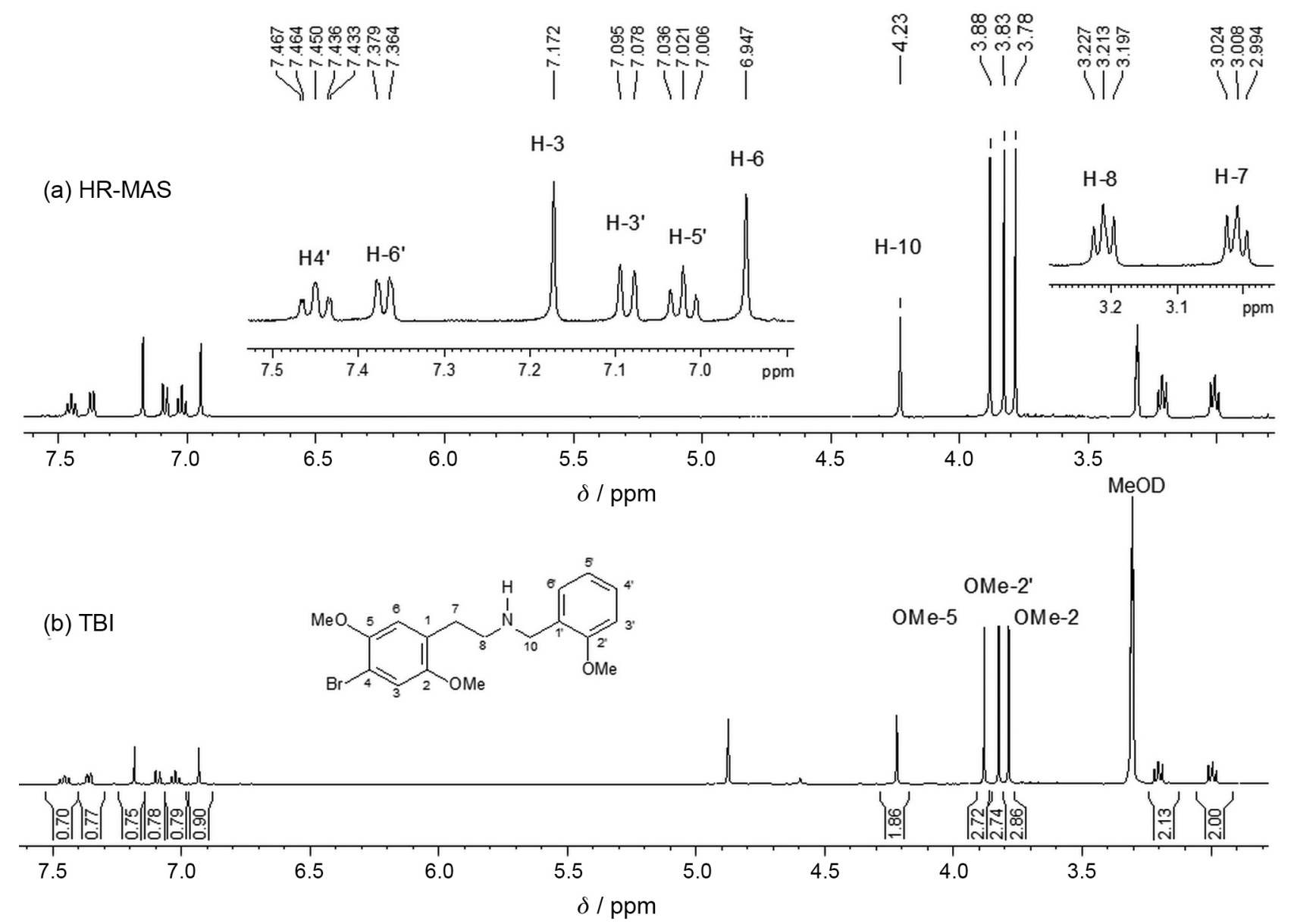

Figure 5. ${ }^{1} \mathrm{H}$ NMR spectra of blotter paper using (a) HR-MAS and (b) TBI probes showing the presence of 25B-NBOMe. The signal multiplicities are highlighted. 
Table 2. ${ }^{1} \mathrm{H}$ NMR spectral data for $25 \mathrm{~B}-\mathrm{NBOMe}\left(500 \mathrm{MHz}, \mathrm{CD}_{3} \mathrm{OD}\right)$

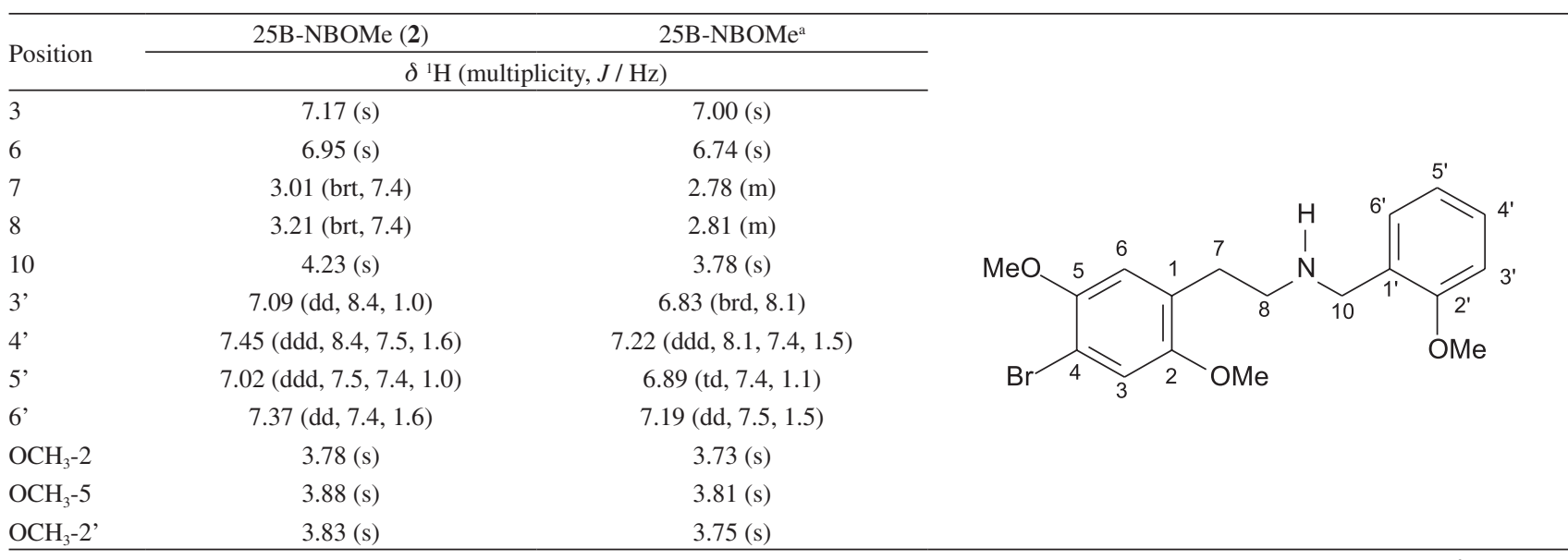

${ }^{a} \mathrm{H}$ NMR spectral data for 2-(4-bromo-2,5-dimethoxyphenyl)- $N$-[(2-methoxyphenyl)methyl]ethanamine (25B-NBOMe) $\left(400 \mathrm{MHz}, \mathrm{CDCl}_{3}\right) .{ }^{18} \delta: \mathrm{chemical}$ shift; $J$ : coupling constant.

major compounds on the mixture of substances, was identified (Figure 6). A $p$-disubstituted aromatic ring was characterized by two doublets at $\delta 7.98$ and 7.39 on ${ }^{1} \mathrm{H}$ NMR spectrum. One methine attached to methyl, methylamine and keto groups was identified on the basis of the quartet signal at $\delta 5.21$, with chemical shift typical

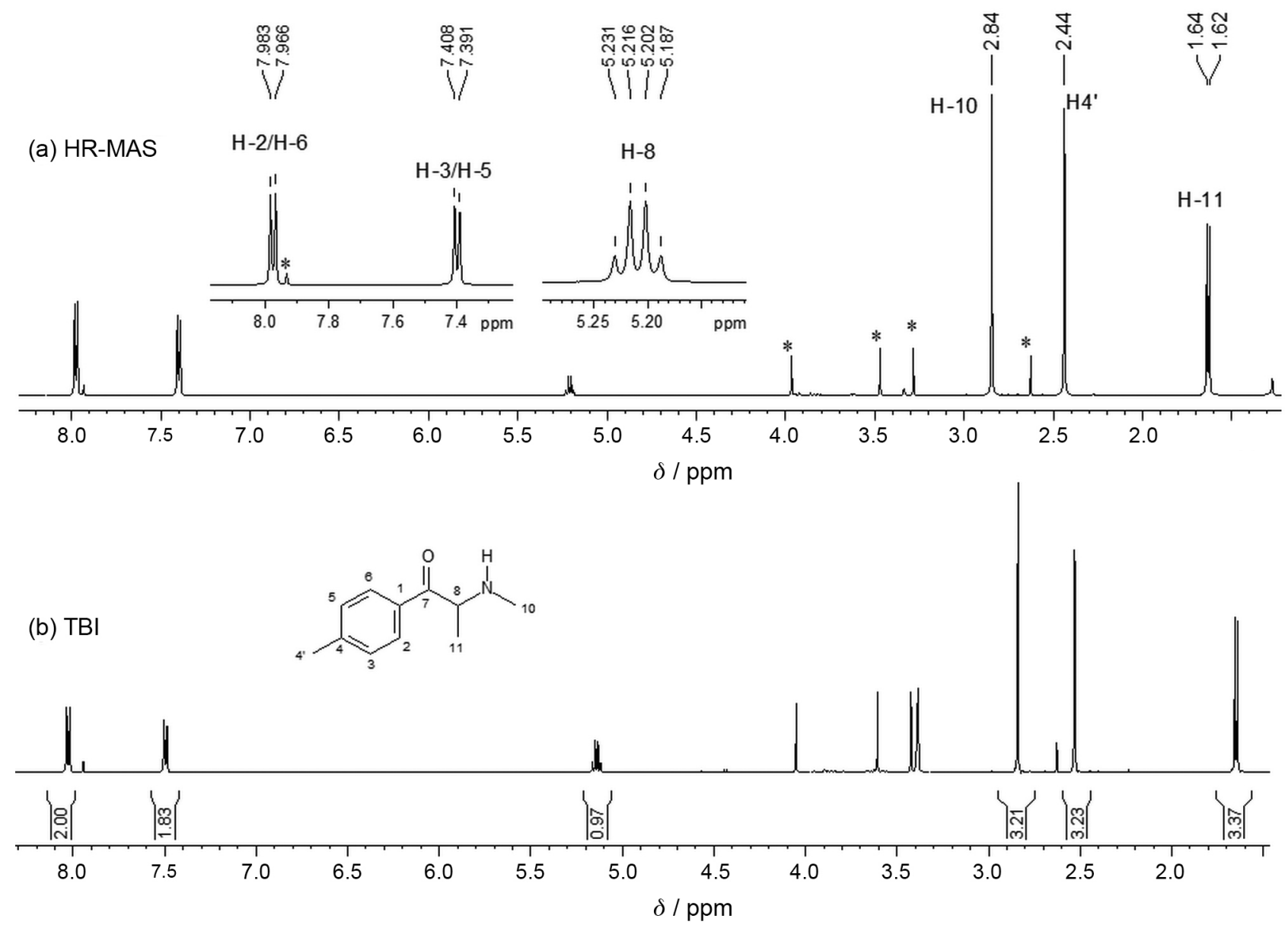

Figure 6. ${ }^{1} \mathrm{H}$ NMR spectra of tablets seized using (a) HR-MAS and (b) TBI probes showing the presence of mephedrone and other compounds $(*$ : caffeine and impurity). The signal multiplicities are highlighted. 
Table 3. ${ }^{1} \mathrm{H}$ NMR spectral data for mephedrone $\left(500 \mathrm{MHz}, \mathrm{CD}_{3} \mathrm{OD}\right)$

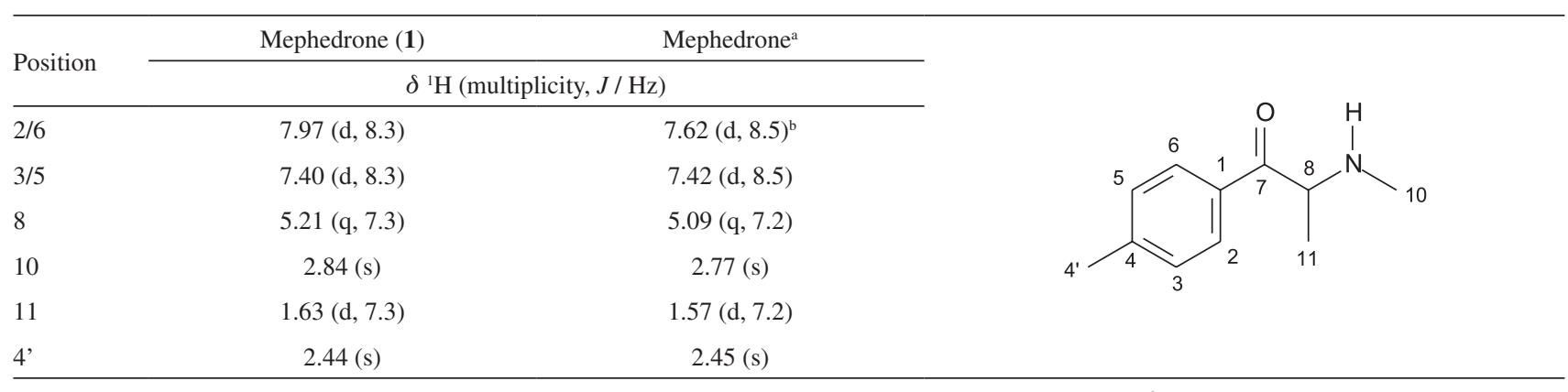

${ }^{a 1} \mathrm{H}$ NMR spectral data for 4-methylmethcathinone (mephedrone) $\left(500 \mathrm{MHz}, \mathrm{CD}_{3} \mathrm{OD}\right) ;{ }^{6}$ brong chemical shift. $\delta$ : chemical shift; $J$ : coupling constant.

of keto and amine neighborhood. Three methyl groups were also identified by two singlets and one doublet signals. This was corroborated by gas chromatographymass spectrometry (GC-MS) (Figure S3). The complete assignment of the mephedrone NMR data is presented in Table 3. In this tablet, caffeine was also observed as a minor compound.

According to previous results, where spectra obtained from in solution or unprocessed samples were always similar, the next seized tablet sample was only analyzed by HR-MAS probe. A 1,4,5-trisubstituted aromatic ring was characterized by one double doublet at $\delta 7.72$ and two doublets at $\delta 7.48$ and 7.00 on ${ }^{1} \mathrm{H}$ NMR spectrum (Figure 7). One methylenedioxy group attached to aromatic ring was identified by the signal at $\delta$ 6.12. Similarly to mephedrone, a keto-amine group was also observed. These NMR data were enough to characterize 3,4-methylenedioxy- $N$-methylcathinone, known as methylone. This was corroborated by GC-MS (Figure S4). The complete assignment of the methylone NMR data is presented in Table 4.

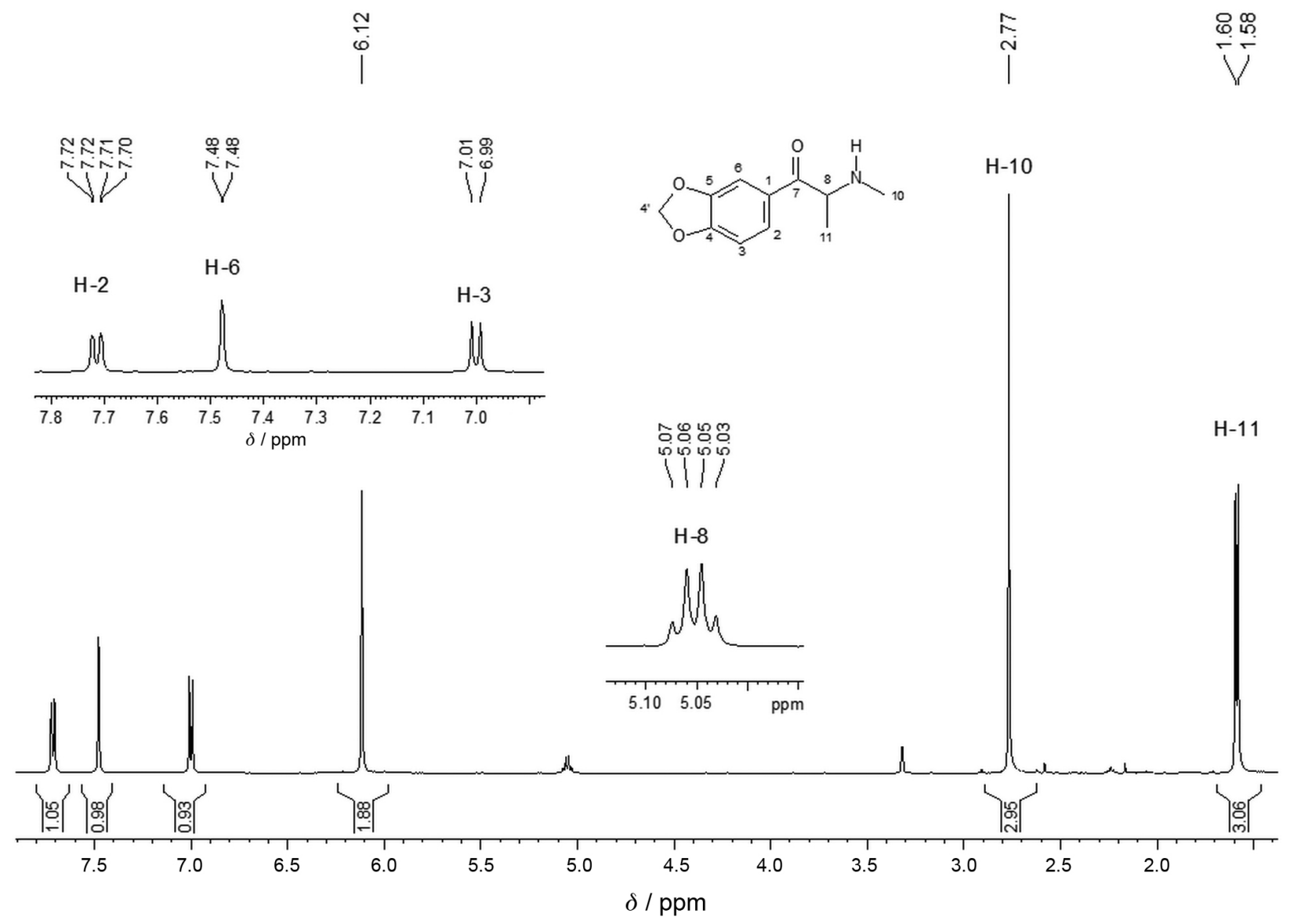

Figure 7. ${ }^{1} \mathrm{H}$ NMR spectrum of a new tablet sample using HR-MAS probe showing the presence of methylone. The signal multiplicities are highlighted. 
Table 4. ${ }^{1} \mathrm{H}$ NMR spectral data for methylone $\left(500 \mathrm{MHz}, \mathrm{CD}_{3} \mathrm{OD}\right)$

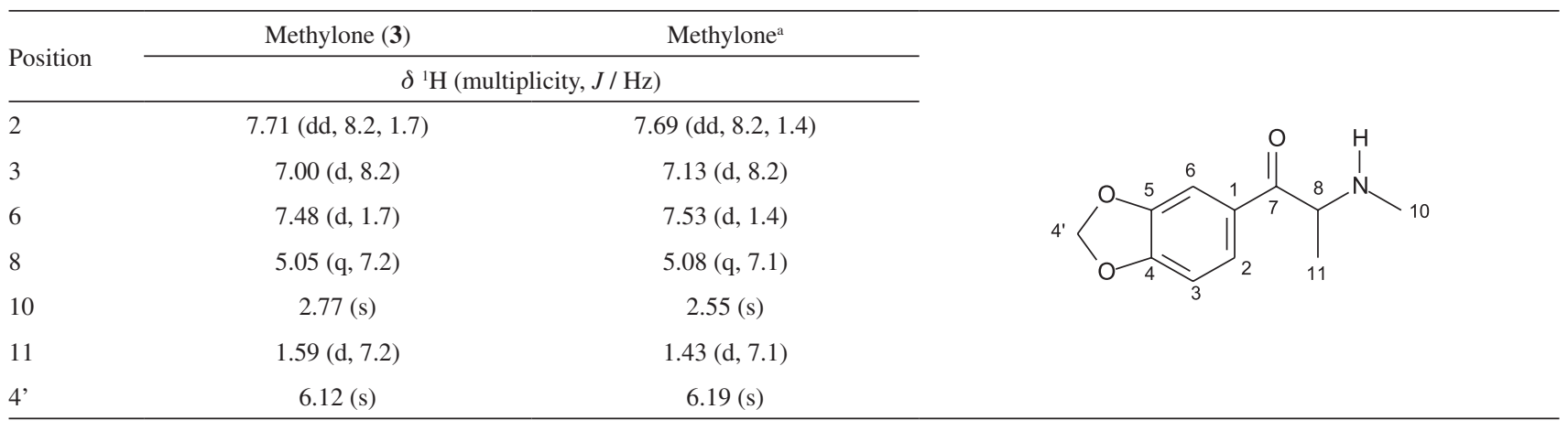

${ }^{a 1} \mathrm{H}$ NMR spectral data for 3,4-methylenedioxy- $N$-methylcathinone (methylone) (400 MHz, DMSO- $\left.d_{6}\right){ }^{7} \delta$ : chemical shift; $J$ : coupling constant.

Thus, the results obtained by ${ }^{1} \mathrm{H}$ HR-MAS NMR technique exhibited an excellent discrimination power for the group of amphetamine derivatives and other molecules with similar chemical structure using minimal sample pretreatment (only powdering).

\section{Conclusions}

In this paper we demonstrated the efficiency of the ${ }^{1} \mathrm{H}$ HR-MAS NMR technique for unambiguous identification of new synthetic illicit substances, using minimal pretreatment of the tablets and blotter paper seized by police department in Goiás State. No significant difference on chemical profile was observed between unprocessed samples or extracted with solvent samples.

The great advantage observed using ${ }^{1} \mathrm{H}$ HR-MAS NMR technique is that no extraction procedure and purification of substances for further analysis was required, thus avoiding a possible contamination and the appearance of artifacts that could compromise the conclusions of the forensic examination. This technique also represents an important time saver, particularly considering the great number of drugs seized in Brazil. Therefore, despite the HR-MAS NMR technique not yet being diffused in forensics area, this work highlights its importance especially due to the limitations presented by traditional techniques compared with the growing emergence of new synthetic psychoactive illegal substances.

\section{Supplementary Information}

Supplementary information is available free of charge at http://jbcs.sbq.org.br as PDF file.

\section{Acknowledgments}

The authors are grateful to Conselho Nacional de
Desenvolvimento Científico e Tecnológico (CNPq), Coordenação de Aperfeiçoamento de Pessoal de Nível Superior (CAPES), Fundação de Amparo à Pesquisa do Estado de Goiás (FAPEG) and Financiadora de Estudos e Projetos (FINEP) for the financial support.

\section{References}

1. Baum, R. M.; Chem. Eng. News 1985, 63, 7.

2. Meyer, M. R.; Maurer, H. H.; Curr. Drug Metab. 2010, 11, 468.

3. http://www.emcdda.europa.eu/publications database?f[0]=field_series_type $\% 253$ Aname\%3AJoint $\% 20$ Reports accessed in March 2016.

4. http://www.emcdda.europa.eu/publications/2015/newpsychoactive-substances accessed in March 2016.

5. Wood, D. M.; Davies, S.; Puchnarewicz, M.; Button, J.; Archer, R.; Ovaska, H.; Ramsey, J.; Lee, T.; Holt, D. W.; Dargan, P. I.; J. Med. Toxicol. 2010, 6, 327 .

6. Gibbons, S.; Zloh, M.; Bioorg. Med. Chem. Lett. 2010, 20, 4135.

7. Maheux, C. R.; Copeland, C. R.; Microgram J. 2010, 7, 42.

8. Uchiyama, N.; Shimokawa, Y.; Matsuda, S.; Kawamura, M.; Kikura-Hanajiri, R.; Goda, Y.; Forensic Toxicol. 2013, 32, 105.

9. Papoutsis, I.; Nikolaou, P.; Stefanidou, M.; Spiliopoulou, C.; Athanaselis, S.; Forensic Toxicol. 2015, 33, 1.

10. Kanai, K.; Takekawa, K.; Kumamoto, T.; Ishikawa, T.; Ohmori, T.; Forensic Toxicol. 2008, 26, 6.

11. United Nations Office on Drugs and Crime; World Drug Report 2014; United Nations: New York, 2014.

12. Rösner, P.; Quednow, B.; Girreser, U.; Junge, T.; Forensic Sci. Int. 2005, 148, 143.

13. Zaitsu, K.; Katagi, M.; Kamata, H. T.; Miki, A.; Tsuchihashi, H.; Forensic Toxicol. 2008, 26, 45.

14. Scientific Working Group for the Analysis of Seized Drugs (SWGDRUG); SWGDRUG Recommendations, v. 7.0; United States Department of Justice: Washington, DC, 2014. 
15. Farooq, H.; Courtier-Murias, D.; Soong, R.; Bermel, W.; Kingery, W. M.; Simpson, A. J.; Curr. Org. Chem. 2013, 17, 3013.

16. Santos, A. D. C.; Fonseca, F. A.; Lião, L. M.; Alcantara, G. B.; Barison, A.; TrAC, Trends Anal. Chem. 2015, 73, 10.
17. Lião, L. M.; Choze, R.; Cavalcante, P. P. A.; Santos, S. C.; Ferri, P. H.; Ferreira, A. G.; Quim. Nova 2010, 33, 634.

18. Hays, P. A.; Casale, J. F.; Microgram J. 2014, 11, 1.

Submitted: February 20, 2016

Published online: April 6, 2016 